\title{
A EVASÃO NOS CURSOS DE LICENCIATURA DA UNEB E OS IMPACTOS NA FORMAÇÃO DOCENTE NO OESTE DA BAHIA
}

\author{
Ana Paula Souza do Prado Anjos ${ }^{1}$ \\ Nilza da Silva Martins ${ }^{2}$ \\ Emilia Karla de Araujo Amaral Pignata ${ }^{3}$
}

Resumo: Observa-se, atualmente, certa regressão das políticas públicas para formação docente e enfraquecimento das Licenciaturas nas Universidades. Nesta perspectiva, o presente trabalho objetiva analisar como a baixa demanda e a evasão nos cursos de Licenciaturas do Departamento de Ciências Humanas da Universidade do Estado da Bahia - Campus IX, localizado na cidade de Barreiras, no extremo oeste baiano, pode interferir na disponibilidade e na qualificação de profissionais para atuar nesta região. Trata-se de um estudo do tipo quantitativo, realizado a partir de análise documental e entrevista. Os resultados apontam não só para desvalorização da profissão docente com a migração de estudantes para cursos de Bacharelado, assim como para a implementação de ações internas e externas nos âmbitos administrativo e pedagógico.

Palavras-chave: Licenciatura; evasão; Docente.

\section{THE EVASION IN UNEB'S LICENSEE COURSES AND IMPACTS IN TEACHING TRAINING IN WEST BAHIA}

\begin{abstract}
There is now a certain regression of public policies for teacher education and weakening of undergraduate degrees in universities. In this perspective, the present study aims to analyze how low demand and avoidance in the undergraduate courses of the Department of Human Sciences of the State University of Bahia - Campus IX, located in the city of Barreiras, in the extreme west of Bahia, may interfere with availability and qualification professionals to work in this region. This is a quantitative study, based on documentary analysis and interview. The results point to the devaluation of the teaching profession with the migration of students to Bachelor courses, as well as the implementation of internal and external actions in the administrative and pedagogical spheres.
\end{abstract}

Keywords: Degree; Evasion; Teacher.

\section{INTRODUÇÃO}

A evasão nos cursos de graduação é um problema que atinge instituições públicas e privadas e têm inúmeras causas.

Para o Ministério da Educação, evasão compreende "a saída definitiva do curso de origem sem conclusão, ou a diferença entre ingressantes e concluintes, após uma geração completa” (MEC, SESU, ANDIFES e ABRUEM, 1996, p. 19). Já a UNEB compreende a evasão como abandono, desistência formalizada, transferência interna e externa e cancelamento de matrícula.

\footnotetext{
${ }^{1}$ Graduada em Pedagogia, Docência e Gestão de Processos Educativos pela Universidade do Estado da Bahia, Campus IX - Barreiras. Especialista em Metodologia de Ensino para Educação Profissional pela UNEB/SUPROF.

${ }^{2}$ Graduada em Pedagogia pela Universidade do Estado da Bahia. Especialista em Supervisão Educacional pela Pontifícia Universidade Católica de Minas Gerais. Mestre em Educação e Contemporaneidade pela Universidade do Estado da Bahia. Doutora em Educação pela Universidade Federal de Goiás. Professora Assistente da Universidade do Estado da Bahia.

${ }^{3}$ Graduada em Pedagogia pela Universidade do Estado da Bahia e Mestre em Educação pela Universidade Católica de Brasília. Docente da Faculdade São Francisco de Barreiras e da Universidade do Estado da Bahia.
} 
A evasão no ensino superior, em especial nas Licenciaturas, é uma problemática que envolve complexas variáveis que precisam ter uma atenção especial das Universidades, no sentido de um acompanhamento sistemático. Esse problema tem refletido diretamente na falta de professores para a educação básica, o que torna o cenário ainda mais preocupante.

Para compreender as causas e consequências da evasão no ensino superior, a Assessoria Pedagógica do Departamento de Ciências Humanas em Barreiras da Universidade do Estado da Bahia (UNEB) realizou, no ano de 2017, uma pesquisa intitulada "Panorama da evasão nos cursos de graduação do DCH - Campus IX, período 2012 a 2016". Os dados coletados estão relacionados aos discentes que ingressaram pelo Sistema de Seleção Unificada (SISU), por vestibular de 2012 a 2016, excluindo-se os que ingressaram por matrícula especial.

A pesquisa foi desenvolvida em duas etapas, tendo estes como objetivos: levantar o quantitativo de ingressantes, evadidos e concluintes nos cursos de graduação do Campus IX, no período de 2012 a 2016; identificar em que período do curso ocorre maior evasão; mapear o perfil dos discentes evadidos de acordo com o tipo de ingresso - vestibular ou do SISU; conhecer os motivos da evasão por curso; fazer levantamento das ações sugeridas pelos discentes evadidos para o Departamento para desenvolver ações para combater a evasão nos cursos de graduação.

Neste artigo, interessa-nos apresentar os dados coletados referentes aos cursos de Ciências Biológicas, Letras, Matemática e Pedagogia - Licenciaturas do Departamento.

Como considerações resultantes da pesquisa, a discussão dos dados abordará elementos que evidencia como a evasão pode impactar direta ou indiretamente na formação de professores.

\section{MATERIAL E MÉTODOS}

A pesquisa realizada foi do tipo quantitativa, por objetivar traçar um panorama do comportamento dos indivíduos de um determinado grupo, neste caso, dos estudantes que evadiram dos cursos do DCH - Campus IX - Barreiras, no período de 04 anos.

Foi utilizado, como instrumento de coleta de dados, um roteiro para análise documental e uma entrevista. A análise documental foi feita na primeira etapa desse estudo, a partir do histórico escolar dos estudantes pesquisados. Foi verificada a situação acadêmica do total de 941 discentes dos cursos de Licenciaturas, sendo Letras 
(184), Pedagogia (418), Ciências Biológicas (187), Matemática (152), que ingressaram no DCH - Campus IX, por meio de vestibular ou SISU, no período de 2012 a 2016.

Na segunda etapa, foi utilizada entrevista por telefone com seis perguntas abertas, relacionadas aos motivos da evasão; as consequências da saída do curso para a vida profissional; a situação acadêmica de estar cursando outra graduação, qual curso, em que instituição e o que o DCH - Campus IX poderia ter feito para evitar essa evasão. Do total de 418 discentes evadidos dos cursos de Licenciaturas, 173 participaram da pesquisa.

A análise realizada foi estatística, com os dados apresentados através de gráficos e tabelas, posteriormente analisados à luz das concepções teóricas que tratam dos motivos, consequências e alternativas necessárias para reverter o cenário de evasão vivenciado pelos cursos de licenciaturas em instituições públicas de ensino superior e que impactam diretamente na qualidade da formação docente.

\section{RESULTADO E DISCUSSÃO}

A Universidade do Estado da Bahia (UNEB), com sede na cidade de Salvador, foi criada no ano de 1983, vinculada à Secretaria de Educação e Cultura do Estado da Bahia. Caracterizada por adotar um sistema multicampi ${ }^{4}$, novas faculdades foram criadas por todo interior do Estado. Em 1986, é fundado o Centro de Ensino Superior de Barreiras - (CESB).

Com a reorganização das Universidades Estaduais Baianas em 1997, a UNEB passou a adotar a estrutura orgânica de departamentos, passando o Campus IX de Barreiras a denominar-se Departamento de Ciências Humanas (DCH).

Totalizando 24 campi e 29 Departamentos, a UNEB, hoje, está presente em grande parte do território baiano, de modo a atender a um universo maior da população, seja através de cursos de graduação, programas especiais, seja por meio de projetos de pesquisa e extensão.

O Departamento de Ciências Humanas (DCH) do Campus IX localiza-se no município de Barreiras, a uma distância de $898 \mathrm{~km}$ da capital do Estado da Bahia. A implantação do Centro de Ensino Superior de Barreiras representou um marco na história do município, colaborando com o processo de desenvolvimento iniciado na década de 70 com os primeiros projetos de agricultura irrigada, acelerados na década de 80 .

\footnotetext{
${ }^{4}$ Estrutura organizacional desconcentrada na sua dispersão físico-geográfica (FIALHO, 2005, p. 20). Esse modelo oportuniza a presença da Universidade nos 26 Territórios de Identidade do Estado da Bahia
} 
Atualmente, o DCH - Campus IX - Barreiras oferece sete cursos de oferta contínua, sendo três Bacharelados (Ciências Contábeis, Engenharia Agronômica e Medicina Veterinária) e quatro Licenciaturas (Ciências Biológicas, Letras, Matemática e Pedagogia).

Este Departamento foi o pioneiro na oferta de cursos de formação de professores na região Oeste da Bahia, contribuindo para a melhoria da qualidade da educação, mas vem enfrentando a crise de permanência dos graduandos nas Licenciaturas, assim como as demais instituições que ofertam essa modalidade de curso no Brasil.

Para compreender a dinâmica da evasão nas Licenciaturas, a pesquisa foi realizada, em sua $1^{\text {a }}$ etapa, entre os meses de abril e outubro de 2017 , tendo como foco comparar o quantitativo de concluintes e evadidos nos cursos de Licenciatura do Campus IX, no período de 2012 a 2016; identificar em que período do curso ocorre maior evasão dos discentes e mapear a forma de ingresso dos discentes evadidos - vestibular ou do SISU.

Ao fazer uma breve caracterização dos estudantes, chamou-nos a atenção que, dos 1.477 ingressantes nos cursos do Campus IX, 75,7\% são do sexo feminino. Esse dado está de acordo com um fenômeno que é realidade em todo o país. Segundo o Instituto Nacional de Estudos e Pesquisas Educacionais Anísio Teixeira (INEP), do total aproximado de 6 milhões de matrículas em cursos de graduação presenciais, 3,4 milhões foram de mulheres, contra 2,7 milhões de homens. "Na conclusão dos estudos, 491 mil alunas formaram-se, enquanto 338 mil homens terminaram seus cursos em 2013” (PORTAL MEC, 2015).

GRÁFICO 1 - Ingressantes Licenciatura - sexo

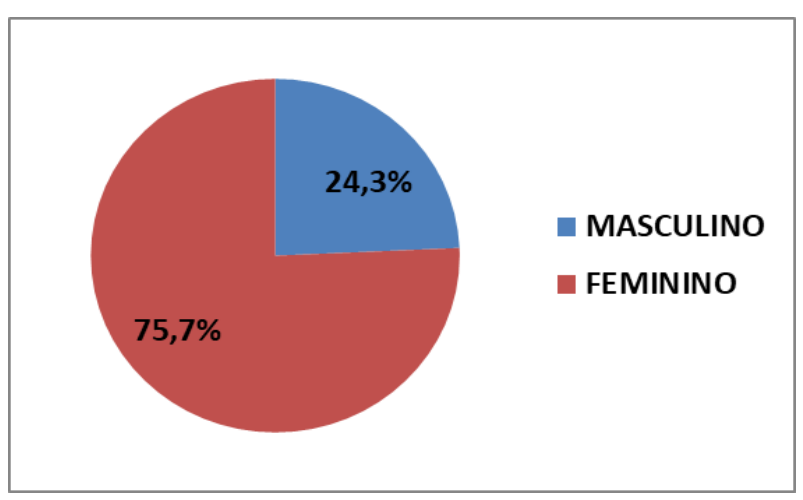

Ainda em relação à caracterização dos ingressantes, outro dado importante é que 66,1\% dos 1.477 ingressantes são da cidade de Barreiras, local sede do Campus. Esse fato diminui a hipótese de que a evasão pode estar relacionada ao distanciamento deste estudante da sua residência. 
Outro aspecto a se considerar é que a UNEB com sua inserção nos municípios representa o acesso à Educação Superior, algo até um tempo atrás inatingível. A interiorização do ensino na proposta de multicampia consolida sua presença em espaços geograficamente isolados, aquém do modelo concentrador de desenvolvimento.

GRÁFICO 2 - Ingressantes por cidade de origem

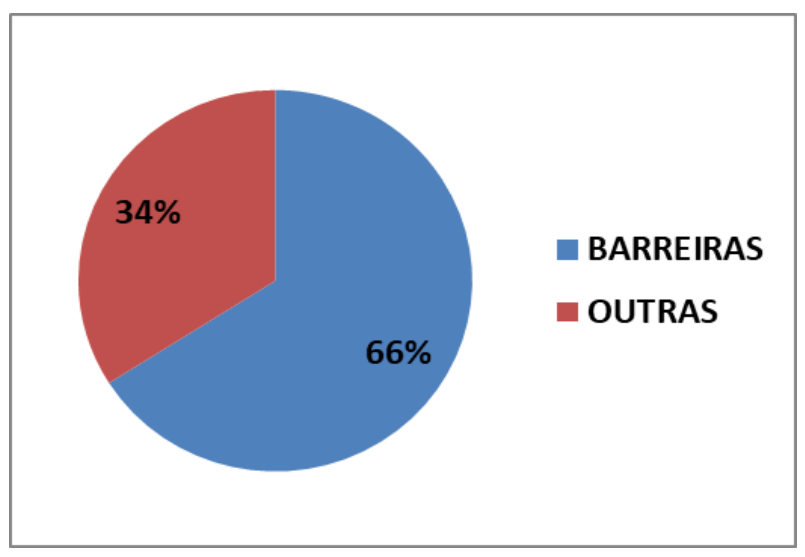

No cenário departamental, dentre as Licenciaturas, o curso de Pedagogia (418) desponta como o que teve maior quantidade de discentes matriculados no período de 2012 a 2016, ingressos pelo SISU ou vestibular, seguido de Ciências Biológicas (187), Letras (184) e Matemática (152), conforme mostra o gráfico abaixo:

GRÁFICO 3 - ingressantes por curso

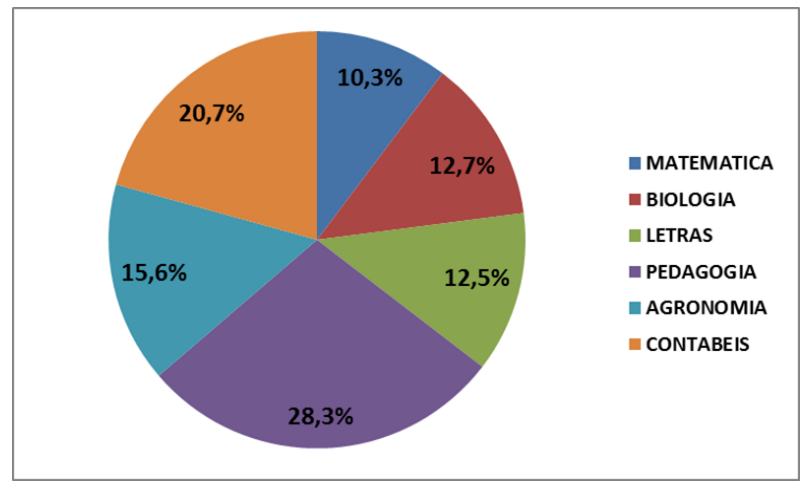

Esses números são muito baixos se compararmos com a demanda por estes cursos em décadas anteriores. Segundo pesquisa realizada pelo Sindicato das

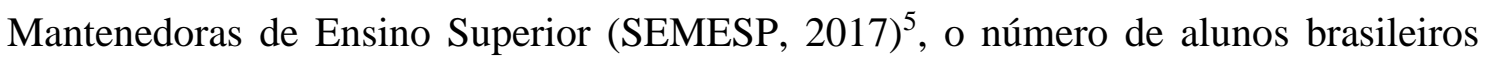
que ingressaram em cursos de Licenciatura presenciais caiu 10\% entre 2010 e 2016.

5 Fonte: Último Segundo - iG @ http://ultimosegundo.ig.com.br/educacao/2017-11-08/cursos-deLicenciatura.html 
Nos quatro anos analisados, 74\% dos estudantes ingressaram através de concurso vestibular e $26 \%$ pelo Sistema de Seleção Unificado (SISU), conforme mostra o Gráfico 4:

GRÁFICO 4 - Ingresso por modalidade de seleção

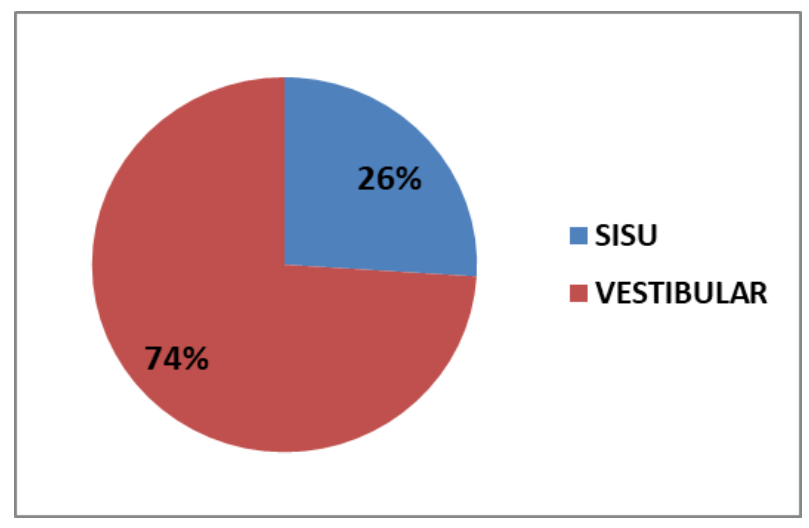

Em se tratando da evasão, faz-se necessário fazer algumas distinções. Polydoro (2000) aponta que existe a evasão do curso, sem a sua conclusão e a evasão do sistema, que é o abandono do sistema universitário. Cardoso (2008) faz referência à evasão aparente e evasão real. A primeira refere-se à mobilidade do aluno de um curso para o outro e a segunda diz respeito à desistência do aluno em cursar o ensino superior. Essa distinção é de suma importância em qualquer análise, para que possamos compreender o processo de migração entre os cursos, no sentido de saber quais cursos estão sendo mais procurados e a evasão real que fornece dados de desistência do ensino superior.

TABELA 1 - Situação acadêmica dos discentes do DCH - Campus IX

\begin{tabular}{|c|c|c|c|c|c|}
\hline \multirow[b]{2}{*}{ CATEGORIA } & \multirow{2}{*}{ SITUAÇÃO DISCENTE } & \multicolumn{2}{|c|}{ LICENCIATURA } & \multicolumn{2}{|c|}{ BACHARELADO } \\
\hline & & $\begin{array}{c}\text { TOTAL } \\
(2012-2016)\end{array}$ & $\%$ & $\begin{array}{c}\text { TOTAL } \\
(2012-2016)\end{array}$ & $\%$ \\
\hline \multirow{5}{*}{ EVADIDOS } & Abandono & 313 & 68,2 & 116 & 21,6 \\
\hline & Desistência Formalizada & 96 & 20,9 & 44 & 8,2 \\
\hline & Desistência do Ingressante & 44 & 9,6 & 12 & 2,2 \\
\hline & Transferência Interna e Externa & 06 & 1,3 & 04 & 0,7 \\
\hline & Subtotal & 459 & 48,7 & 176 & 32,8 \\
\hline \multirow{5}{*}{$\begin{array}{c}\text { DEMAIS } \\
\text { DISCENTES }\end{array}$} & Diplomados & 47 & 5,0 & 52 & 9,7 \\
\hline & Matriculados & 425 & 45,2 & 298 & 55,6 \\
\hline & Trancamento & 09 & 1,0 & 10 & 1,9 \\
\hline & Subtotal & 482 & 51,3 & 360 & 67,2 \\
\hline & TOTAL GERAL & 941 & 100 & 536 & 100 \\
\hline
\end{tabular}


O abandono constitui o tipo de evasão predominante nos cursos, seguido pela desistência formalizada. A desistência do ingressante também representa um dado considerável e ocorre, geralmente, com alunos que ingressaram pelo SISU, que cancelam a matrícula para ingressar em outro curso. A evasão na Licenciatura totaliza quase $50 \%$ dos matriculados, percentual considerado alto.

Lima e Machado (2014) afirmam que:

\begin{abstract}
A atividade profissional do magistério no Brasil não tem se mostrado atraente. Os baixos salários, as precárias condições de trabalho, a falta de segurança nas escolas, o desprestígio social da atividade e a falta de perspectivas na carreira contribuem para que cada vez menos pessoas se interessem pela profissão (p. 126).
\end{abstract}

Certamente, essas são variáveis que representam a realidade da profissão docente em todo o país. O processo de desvalorização do professor, associado ao desmonte da educação pública, tem acarretado altos índices de desistência da profissão, bem como uma baixa autoestima naqueles que permanecem.

A título de comparação, a Tabela 1 mostra os mesmos dados, só que referentes aos cursos de Bacharelado, cujos números caem, respeitada a proporcionalidade.

Em ambos os casos (Licenciaturas ou Bacharelados), o abandono constitui o tipo de evasão predominante nos cursos, o que representa grande prejuízo para a Universidade, mas, principalmente para a sociedade, pois as vagas residuais nem sempre são preenchidas em matrícula especial, a partir de qual são selecionados novos discentes que solicitam vagas por transferência, rematrícula ou portador de diploma.

Para Silva Filho (2007, p. 642) "as perdas de estudantes que iniciam, mas não terminam seus cursos são desperdícios sociais, acadêmicos e econômicos".

Em relação ao perfil dos estudantes que evadem dos cursos de Licenciatura, a pesquisa demonstrou que o maior percentual é do sexo feminino, proporcionalmente ao ingresso nos cursos, que é predominante de mulheres $(68,2 \%)$. Considerando também que o ingresso se dá, em sua maioria, por pessoas residentes na cidade de Barreiras, sede do Campus $(66,1 \%)$, o percentual de evasão destes sujeitos também foi maior.

Em relação à modalidade de seleção, evadem mais os ingressantes pelo processo seletivo no formato "vestibular". Porém, a diferença é muito pequena em relação aos evadidos pela modalidade SISU, para merecer análise mais minuciosa. 
GRÁFICO 5 - Evasão por modalidade de seleção

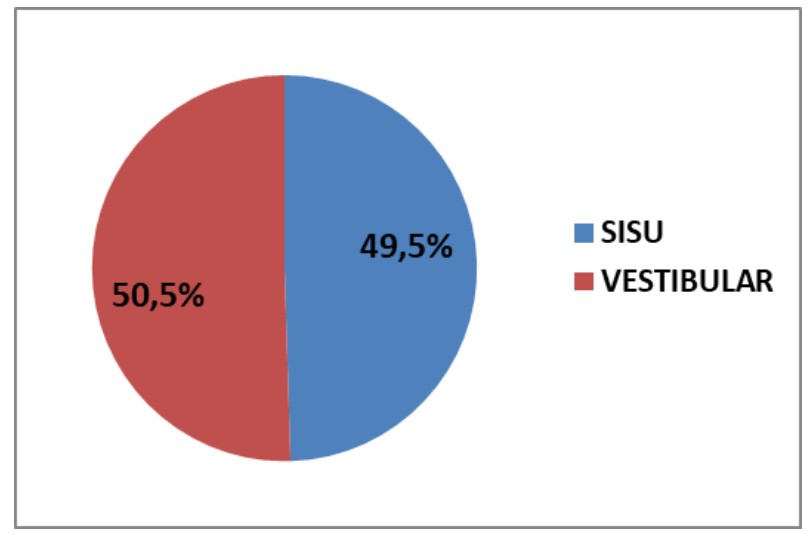

Já em se tratando da evasão por semestre, os dados apontam para a importância de uma análise mais aprofundada. Um estudo feito pela Comissão Especial (MEC, SESU, ANDIFES e ABRUEM, 1996) apontou que, já no primeiro semestre, muitos estudantes começam a evadir-se por causa da precária formação escolar prévia. "Logo, o ingresso em um curso superior sem a preparação necessária reforça as dificuldades que muitos enfrentarão no decorrer da graduação" (LIMA E MACHADO, 2014 p. 125). Outro aspecto apontado está relacionado a dificuldades financeiras, pois "parcela significativa desses estudantes faz parte da classe economicamente desfavorecida, em termos de renda familiar ou pessoal” (MEC, SESU, ANDIFES e ABRUEM, 1996, p. 139).

Além desses fatores, que estão diretamente relacionados à vida do estudante, a comissão indicou, também, possíveis fatores internos às instituições, específicos da estrutura e dinâmica de cada curso, que podem contribuir para a evasão:

[...] currículos desatualizados, alongados; rígida cadeia de pré-requisitos, além da falta de clareza sobre o próprio projeto pedagógico do curso; [...] questões didático-pedagógicas: por exemplo, critérios impróprios de avaliação do desempenho discente; [...] falta de formação pedagógica ou ao desinteresse do docente; vinculados à ausência ou ao pequeno número de programas institucionais para o estudante, como Iniciação Científica, Monitoria, programas PET (Programa Especial de Treinamento), etc.; [...] cultura institucional de desvalorização da docência na graduação, de insuficiente estrutura de apoio ao ensino de graduação: laboratórios de ensino, equipamentos de informática, etc.; inexistência de um sistema público nacional que viabilize a racionalização da utilização das vagas, afastando a possibilidade da matrícula em duas universidades. (MEC, SESU, ANDIFES e ABRUEM, 1996, p. 28).

Em relação ao semestre letivo que registra o maior índice de evasão, em todos os cursos do DCH - Campus IX, ocorre um aumento significativo no segundo semestre. Pode- 
se afirmar que este é o período em que a maioria decide, de fato, se tem afinidade ou não com o curso escolhido. Logo, este semestre requer-se maior atenção dos colegiados no acompanhamento aos discentes. Um dos aspectos que precisa ser considerado é a maneira como a universidade apresenta aos ingressantes o curso. Nestes primeiros semestres, precisamos de professores motivadores, comprometidos com a docência e referências para estes estudantes. O gráfico abaixo mostra, acentuadamente, essa realidade.

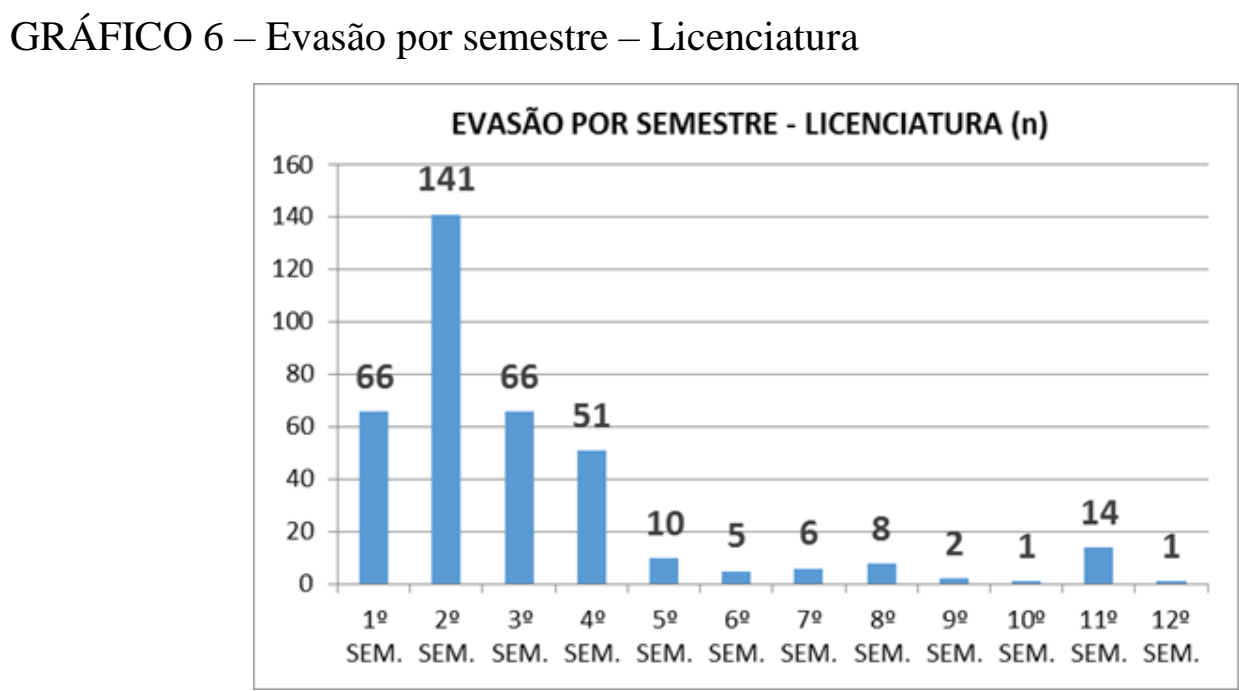

Outro fato preocupante que merece especial atenção é a evasão a partir do $7^{\circ}$ semestre do curso, ou seja, o discente, praticamente em fase de conclusão, abandona o curso, depois de tanto custo para a Universidade e para o próprio graduando. Este fato precisa ser mais bem aprofundado e diz respeito ao percurso deste graduando. Quais componentes curriculares não foram capazes de articular os conhecimentos construídos com as vivências práticas que, nesta fase do curso, são exigidas?

Fazendo uma análise por Licenciatura, o curso de Matemática é o que registra o maior índice de evasão, seguido do curso de Ciências Biológicas.

GRÁFICO 7 - Evasão por curso - Licenciatura

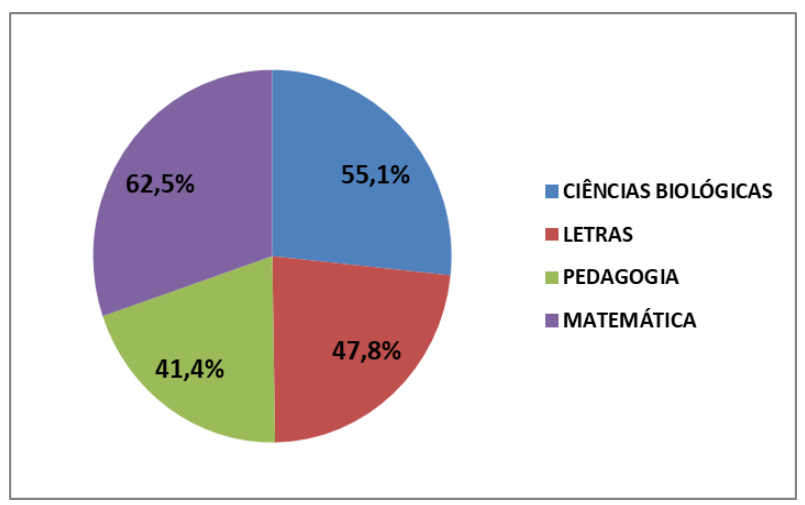


O curso de Matemática tem apresentado a menor concorrência no vestibular, segundo relatórios de concorrência no processo seletivo divulgado pela UNEB. É o curso com a menor quantidade de discentes matriculados e com o maior índice de evasão no Departamento de acordo com dados do SAGRES. Uma informação importante nesta análise é que em Barreiras existem três Instituições Públicas ${ }^{6}$ de nível superior que oferecem o curso de Matemática. Situação semelhante em relação ao número de discentes matriculados também acontece com os cursos de Ciências Biológicas e Letras que apresentam baixa concorrência e altos índices de evasão.

Para Andriola et al. (2006), a falta de informação acerca do curso e da carreira escolhida pode ser fator responsável pela evasão discente. Além dessa possível desinformação, o autor aponta para a falta de embasamento teórico e dificuldade para conciliar estudo e trabalho como possíveis obstáculos que podem surgir durante a vida acadêmica, além de dificuldades financeiras.

O fato de os cursos menos concorridos serem justamente os que não conseguem assegurar a permanência dos discentes pode estar diretamente relacionado ao que afirma o autor quando aponta a falta de embasamento teórico, visto que ingressam nos cursos de menor concorrência estudantes com menor pontuação nos processos seletivos.

Em se tratando do tempo de permanência na Universidade, 78,7\% dos 47 estudantes que concluíram uma Licenciatura no Campus IX passaram mais tempo do que o previsto para conclusão dos cursos. Somente $21,3 \%$ conseguiram finalizar no tempo previsto. A título de comparação, esse fenômeno não ocorre com tanta representatividade nos Bacharelados, conforme fica evidente no Gráfico 8.

GRÁFICO 8 - Tempo de permanência nos cursos do DCH - Campus IX (\%)

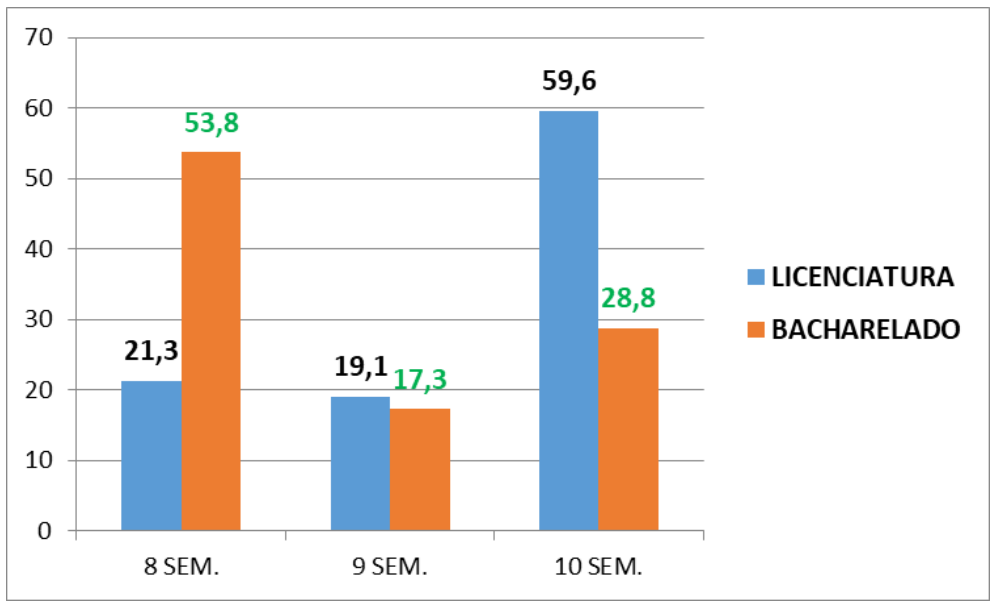

${ }^{6} \mathrm{O}$ curso de Matemática é oferecido pela Universidade do Estado da Bahia, pelo Instituto Federal da Bahia (IFBA - Campus de Barreiras) e pela Universidade Federal do Oeste da Bahia (UFOB). 
No que se refere ao percentual de concluintes por curso, a Licenciatura em Pedagogia, apesar de ter uma quantidade maior de ingressantes, é a que registra o menor quantitativo de diplomados e o maior tempo de atraso para a conclusão do curso. Esse fato na Pedagogia é recorrente apesar de ser o curso que mais tem profissionais formados em Barreiras. Essa situação pode ser associada à ausência de cursos stricto sensu na cidade que permitam a formação exigida nas seleções e nos concursos públicos. O curso de Matemática foi o que registrou maior número de discentes que colaram grau.

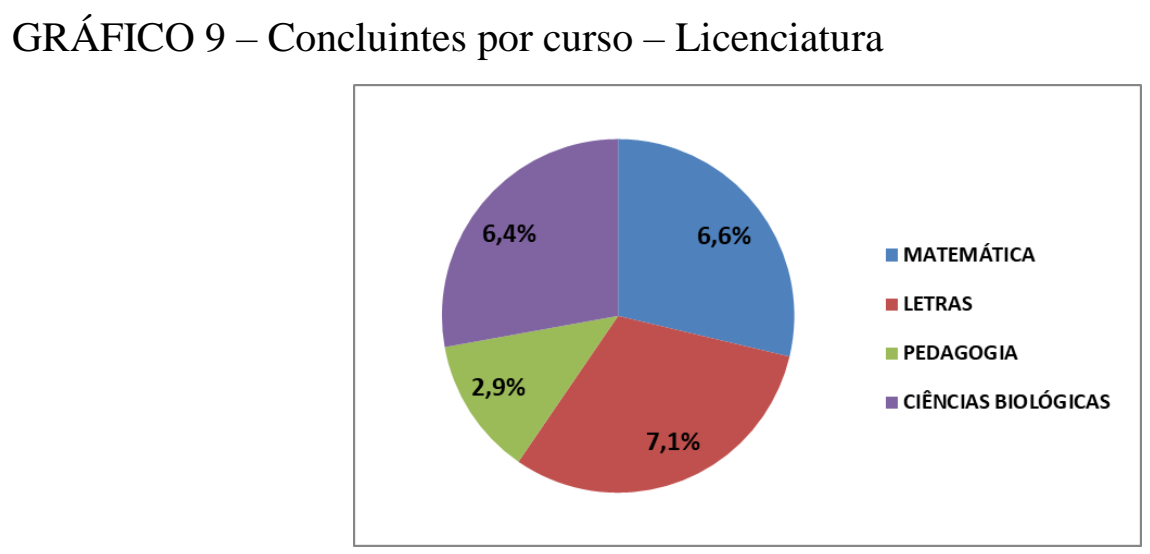

Na segunda etapa da coleta de dados, buscamos conhecer os motivos que levaram à evasão em cada curso. Ao detectarmos que grande parte evadiu por ter sido aprovado em outro curso, buscamos, também, identificar os cursos e instituições escolhidos pelos discentes evadidos. Também foi objetivo desta etapa fazer um levantamento das ações sugeridas pelos discentes evadidos para que o Departamento possa desenvolver ações no combate à evasão.

GRÁFICO 10 - Motivos da evasão (\%)

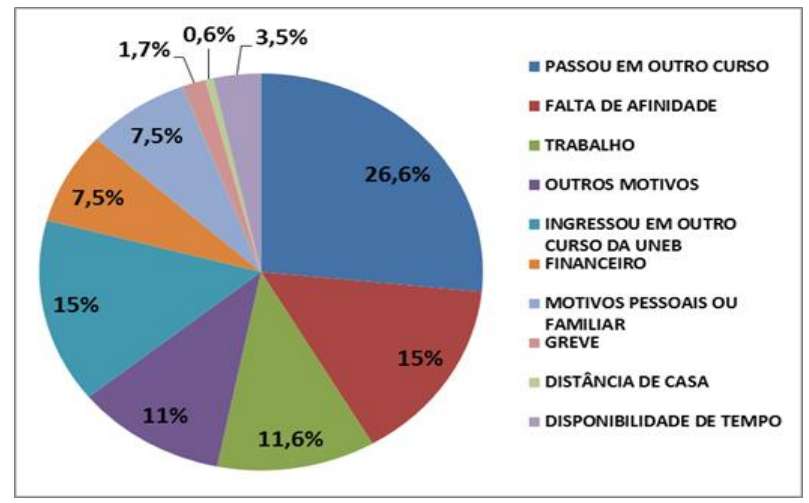

O ingresso em outro curso da UNEB ou em outra instituição sobressai como principal motivo informado, seguido da falta de afinidade pelo curso. Questões 
relacionadas a trabalho também têm levado muitos graduandos a saírem da Universidade. Em relação à questão da afinidade, um dos aspectos que pode ser associado a ela pode ser a motivação e o envolvimento dos professores que atuam nos primeiros semestres. Quando o estudante convive com espaços motivadores, instigadores, envolventes, a tendência natural é também sentir-se motivado. Neste sentido, Freire (1999) argumenta que:

O meu envolvimento com a prática educativa, sabidamente politica, moral, gnosiológica, jamais deixou de ser feito com alegria, o que não significa dizer que tenha invariavelmente podido criá-la nos educandos. Mas, preocupado com ela, enquanto clima ou atmosfera do espaço pedagógico, nunca deixei de estar. (p.72)

Essa prática engajada, respaldada no compromisso social e político, são construtores de novos olhares nos futuros docentes.

A boa notícia é que parcela significativa (74\%) dos discentes evadidos conseguiu ingressar em outro curso de graduação e, conforme relatos, estão matriculados ou já conseguiram concluir o curso escolhido, além de se mostrarem satisfeitos com a nova área escolhida.

Logo, está acontecendo um processo de migração de curso ou instituição, que, conforme a concepção apresentada por Ristoff (1995), denomina-se de mobilidade discente. Como os discentes estão conseguindo reingressar no ensino superior e com maior satisfação, o prejuízo social, profissional e acadêmico para este é praticamente nulo.

Vale registrar que o desinteresse pelas Licenciaturas tem se intensificado. Apenas 36\% dos evadidos dos cursos do Departamento ingressaram em algum curso de Licenciatura. Dos discentes que migraram para Licenciatura, boa parte ingressou em cursos ofertados pelo próprio Departamento e os demais escolheram cursos da Universidade Federal do Oeste da Bahia.

Gráfico 11 - Modalidade de curso escolhido (\%)

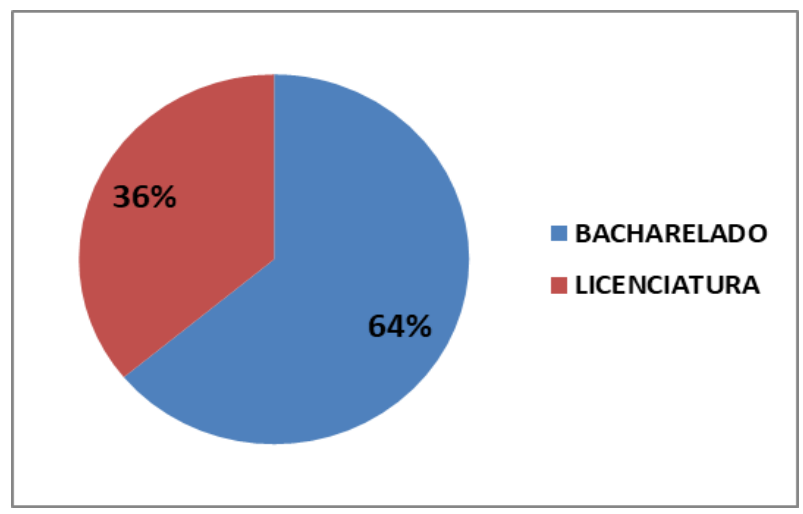


Quando solicitados a indicarem ações para que o Departamento pudesse investir na prevenção e diminuição da evasão, a maioria afirmou não ter sugestões a dar. Isso se deve ao fato de a maioria dos evadidos ter saído, antes de completar dois semestres de curso, e, por isso, não conseguiram vivenciar as atividades da Universidade no seu tripé de ensino, pesquisa e extensão.

GRÁFICO 12 - Ações sugeridas para diminuir a evasão no curso (\%)

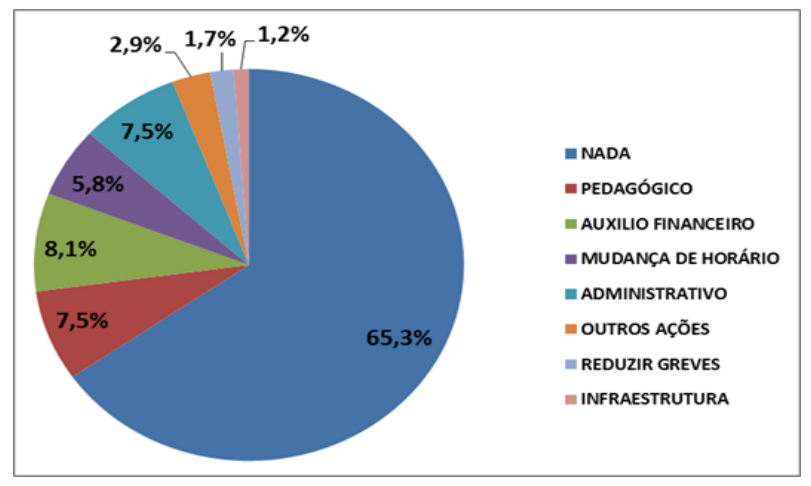

Entre as sugestões, estão o maior comprometimento dos docentes com o ensino e com o cumprimento da carga horária, o maior acompanhamento aos ingressantes por parte dos colegiados, a oferta de disciplinas em apenas um turno, a ampliação das bolsas de auxílios aos estudantes, as melhorias na infraestrutura dos laboratórios, a redução da quantidade e o tempo de greve docente etc.

As sugestões apontadas estão relacionadas aos aspectos pedagógicos e administrativos. O docente de um curso de Licenciatura precisa ter em mente a importância de sua tarefa na formação de professores, que, atualmente, passa por situações muito complexas. Portanto, esse docente, além de se preocupar com sua formação para desenvolver um trabalho de qualidade, precisa transmitir em seus atos o compromisso com sua profissão. “[...] Como ser educador, se não desenvolvo em mim a indispensável amorosidade aos educandos com quem me comprometo e ao próprio processo formador de que sou parte?" (FREIRE, 1999, p.67).

\section{CONSIDERAÇÕES FINAIS}

A trajetória dessa incursão epistemológica tem revelado a complexidade dos cursos de Licenciatura em nossa sociedade, ao mesmo tempo em que sabemos da sua importância e do papel de que docentes comprometidos com sua formação podem exercer na sociedade. Os dados oriundos desta pesquisa suscitam ações pedagógicas e 
administrativas que precisam ser concretizadas no DCH - Campus IX - Barreiras. Vislumbramos ações internas e externas. As internas estão relacionadas aos Colegiados de Curso, aos professores, ao Projeto Político Pedagógico das respectivas Licenciaturas. As questões administrativas no tocante à melhoria do espaço físico, à ampliação de programas de permanência dos estudantes na graduação, à construção de laboratórios podem traduzir em melhoria das Licenciaturas. Em nível externo, podemos fomentar as parcerias com as escolas de Educação Infantil, Ensino Fundamental I e II para que nossos estudantes possam, já nos primeiros semestres, construir laços com a Educação Básica e ir se apropriando do ofício de ser docente.

Recebido em: 30-05-2018 Aceito em: 10-07-2018

\section{REFERÊNCIAS}

ANDRIOLA, Wagner Bandeira; ANDRIOLA, Cristiany Gomes and MOURA, Cristiane Pascoal. Opiniões de docentes e de coordenadores acerca do fenômeno da evasão discente dos cursos de graduação da Universidade Federal do Ceará (UFC). Ensaio: Ceará (UFC). Ensaio: Avaliação e Políticas Públicas em Educação [online]. 2006, vol.14, n.52, pp.365-382. ISSN 0104-4036. http://dx.doi.org/10.1590/S0104-40362006000300006.

BRASIL. Ministério da Educação. Comissão Especial de Estudos sobre a Evasão nas Universidades Públicas Brasileiras - ANDIFES/ABRUEM/SESu/MEC. Diplomação, Retenção e Evasão nos Cursos de Graduação em Instituições de Ensino Superior Públicas, Outubro de 1996.

CARDOSO, Claudete Batista. Efeitos da política de cotas na Universidade de Brasília: uma análise do rendimento e da evasão. 2008. 123f. Dissertação (Mestrado em Educação) - Universidade de Brasília - UNB-Brasília, 2008.

FREIRE, Paulo. Pedagogia da autonomia: saberes necessários a pratica educativa. São Paulo: Paz e Terra, 1996.

LIMA, Edileusa; MACHADO, Lucília. A evasão discente nos cursos de Licenciatura da Universidade Federal de Minas Gerais. Revista de Educação da Unisinos. 18(2):121-129, maio/agosto 2014.

POLYDORO, Soely Aparecida Jorge. O trancamento de matrícula na trajetória acadêmica do universitário: condições de saída e de retorno à instituição. 2000. 145f. Tese (Doutorado em Educação) - Universidade Estadual de Campinas UNICAMP - Campinas, SP, 2000.

RISTOFF, Dilvo. Evasão: exclusão ou mobilidade. Santa Catarina, UFSC, 1995.

SILVA FILHO, Roberto Leal Lobo e; MOTEJUNAS, Paulo Roberto; HIPOLITO, Oscar e LOBO, Maria. 2007. A evasão no Ensino Superior Brasileiro. Cadernos de 
Pesquisa, [online]. 2007, vol.37, n.132, pp.641-659. ISSN 0100-1574. http://dx.doi.org/10.1590/S0100-15742007000300007.37. 